\title{
Predictors of Epstein-Barr virus serostatus and implications for vaccine policy: A systematic review of the literature
}

\author{
Joanne R Winter ${ }^{1}$, Charlotte \\ Jackson ${ }^{1,2}$, Joanna EA \\ Lewis $^{3^{*}}$, Graham S Taylor ${ }^{*}$, \\ Olivia G Thomas ${ }^{4}$, Helen R \\ Stagg 1,5 \\ ${ }^{1}$ Centre for Molecular Epidemiology \\ and Translational Research, Institute \\ for Global Health, University College \\ London, London, UK \\ ${ }^{2}$ MRC Clinical Trials Unit, University \\ College London, London, UK \\ ${ }^{3}$ National Institute for Health Research \\ (NIHR) Health Protection Research \\ Unit in Modelling Methodology and \\ Medical Research Council Centre for \\ Outbreak Analysis and Public Health, \\ Department of Infectious Disease \\ Epidemiology, Imperial College \\ London, London, UK \\ ${ }^{4}$ Institute of Immunology and \\ Immunotherapy, College of Medical \\ and Dental Sciences, University of \\ Birmingham, Birmingham, UK \\ ${ }^{5}$ Usher Institute, University of \\ Edinburgh, Edinburgh, UK \\ * Contributed equally and listed \\ alphabetically.
}

Background Epstein-Barr virus (EBV) is an important human pathogen; it infects $>90 \%$ people globally and is linked to infectious mononucleosis and several types of cancer. Vaccines against EBV are in development. In this study we present the first systematic review of the literature on risk factors for EBV infection, and discuss how they differ between settings, in order to improve our understanding of EBV epidemiology and aid the design of effective vaccination strategies.

Methods MEDLINE, Embase, and Web of Science were searched on $6^{\text {th }}$ March 2017 for observational studies of risk factors for EBV infection. Studies were excluded if they were published before 2008 to ensure relevance to the modern day, given the importance of influencing future vaccination policies. There were no language restrictions. After title, abstract and full text screening, followed by checking the reference lists of included studies to identify further studies, data were extracted into standardised spreadsheets and quality assessed. A narrative synthesis was undertaken.

Results Seventy-seven papers met our inclusion criteria, including data from 31 countries. There was consistent evidence that EBV seroprevalence was associated with age, increasing throughout childhood and adolescence and remaining constant thereafter. EBV was generally acquired at younger ages in Asia than Europe/North America. There was also compelling evidence for an association between cytomegalovirus infection and EBV. Additional factors associated with EBV seroprevalence, albeit with less consistent evidence, included ethnicity, socioeconomic status, other chronic viral infections, and genetic variants of HLA and immune response genes.

Conclusions Our study is the first systematic review to draw together the global literature on the risk factors for EBV infection and includes an evaluation of the quality of the published evidence. Across the literature, the factors examined are diverse. In Asia, early vaccination of infants would be required to prevent EBV infection. In contrast, in Western countries a vaccine could be deployed later, particularly if it has only a short duration of protection and the intention was to protect against infectious mononucleosis. There is a lack of high-quality data on the prevalence and age of EBV infection outside of Europe, North America and South-East Asia, which are essential for informing effective vaccination policies in these settings.

Epstein-Barr Virus (EBV) is a herpesvirus that infects 90\%-95\% of humans, causing lifelong infection [1,2]. EBV infection during childhood is generally asymptomatic, however acquisition of EBV during adolescence or early adulthood often causes infectious mononucleosis (IM) [3]. EBV is associated with $1 \%$ of global cancers, particularly Hodgkin's lymphoma, Burkitt's lymphoma, nasopharyngeal cancer (NPC) and gastric cancer [4]. 
EBV infection is not currently treatable or preventable by vaccination, although the National Institutes of Health have stated that an EBV vaccine is an important goal [5]. Vaccines are currently in development which could protect against EBV infection or EBV-associated disease [6]. It is critical for vaccine development to know the target product profile for a potential vaccine, which is only possible with a good understanding of the underlying epidemiology of infection and disease.

The epidemiology of EBV infection is not well understood. Seroprevalence increases with age, and seropositivity appears to occur at younger ages in resource-limited countries [7,8]. Whilst $90 \%-95 \%$ of people are infected by age 25 , a small proportion (5\%-10\%) remain seronegative throughout their life [9]. EBV infection is correlated with human cytomegalovirus (CMV) infection $[10,11]$, another herpesvirus which infects a high proportion of the population from a young age and is linked to reduced life expectancy [12]. Unlike CMV, the impact of EBV seronegativity on the life course is unknown. Our immune systems and EBV are likely well-adapted to each other, given the co-evolution of humans and virus [13,14]. Beyond this, studies of EBV epidemiology are sparse, and there has been no attempt to synthesise the global literature on the factors associated with EBV serostatus. Such syntheses are critical, as a greater understanding of EBV epidemiology, including the dynamics of EBV infection in different sub-populations and the long-term health impacts of remaining EBV-seronegative, will be necessary for the vaccine development.

Given the importance of systematically collating, describing and formal critical evaluations of the evidence, we conducted the first systematic epidemiological literature review of risk factors for EBV infection, and discuss the implications of our findings for future EBV vaccination policy.

\section{METHODS}

\section{Search strategy and study selection}

MEDLINE, Embase, and Web of Science were searched on 6th March 2017 for articles on risk factors for EBV infection. The search terms included variations of 'human herpesvirus 4', 'Epstein-Barr virus', 'infectious mononucleosis', 'glandular fever', 'serostatus', 'risk factor', 'cross-sectional study', 'cohort study', 'case-control study', 'clinical trial' and 'human'; the full search terms are shown in Supplementary item 1. Studies published before 2008 were excluded to ensure that the risk factors reported are relevant in the present day. Title, abstract and full-text screening was split between HRS and CJ, with 10\% overlap. Disagreements were resolved by consensus. Studies were included if they contained data on the percentage of people with antibodies against EBV stratified by age or any other risk factor. Studies were excluded if they examined risk factors for EBV-associated disease (eg, IM, cancers or autoimmune conditions) rather than infection, if there was no comparison group, or if they did not include original research (reviews, editorial pieces, case reports).

\section{Data extraction, synthesis and quality assessment}

Data extraction and quality assessment was split between HRS and JRW, with 10\% overlap to ensure consistency. Data were extracted into a pre-designed spreadsheet that recorded the study design, study population, and EBV seroprevalence, stratified by risk factor. Discrepancies between reviewers were resolved by consensus. Studies published in languages other than English were extracted by an additional reviewer, with additional quality control by JRW. Where studies reported data on risk factors for multiple EBV antigens, we report data only for the most commonly reported antigen (EBV viral capsid antigen, VCA), but state where other data were available. As there was substantial heterogeneity in study design, reporting and the risk factors examined, we present a narrative synthesis of our findings in place of a meta-analysis.

The quality of included studies was assessed using a checklist adapted from Downs and Black [15], as per the guidance issued by Deeks et al [16]. Sufficient adjustment for confounding was defined as adjusting for age, sex, ethnicity or country of birth, and some measure of socioeconomic status; this was a pragmatic decision based on common confounders and prior knowledge. For the purposes of the sample size calculation, age was treated as the main exposure of interest. As per Downs and Black, when assessing the power of studies, we calculated the minimum sample size per strata that would be required to detect a change in EBV seroprevalence from 95\% to 85\%, with power ranging from 70\%-99\%. Conservatively, we assumed only two strata and a ratio of 1:1 between exposure strata. Different thresholds were used for case-control studies and for cohort or cross-sectional studies. These criteria were scored from $0(<70 \%$ power) to 5 ( $>99 \%$ power $)$.

This review was registered on PROSPERO (CRD42017059811). 


\section{RESULTS}

\section{Search results and included studies}

Our literature search yielded 22074 results after de-duplication. After exclusion of papers published before 2008 ( $\mathrm{n}=11600)$, and title, abstract and full-text screening (Figure 1), 77 studies were included (Table S1 in the Online Supplementary Document). Three otherwise eligible studies were excluded; one as all participants were seropositive for EBV, one as only one patient was seronegative and one study which was a meta-analysis of the association between latitude and EBV seroprevalence which defined latitude based on the study location rather than participant-level data. Studies ranged in size from 8-61 273 participants, EBV seroprevalence ranged from 6\%-91\%. The global distribution of studies is shown in Figure 2. There were 12 case-control studies (3 nested within cohorts), 13 cohort/longitudinal and 16 which reported only cross-sectional results but were part of cohort. Thirty-three were cross-sectional, and the design of two other retrospective studies was unclear.

Study populations included population-level studies of healthy individuals $(n=42)$, pregnant women $(n=3)$ and healthy family members of people with NPC $(n=3)$, and studies of specific patient popula-

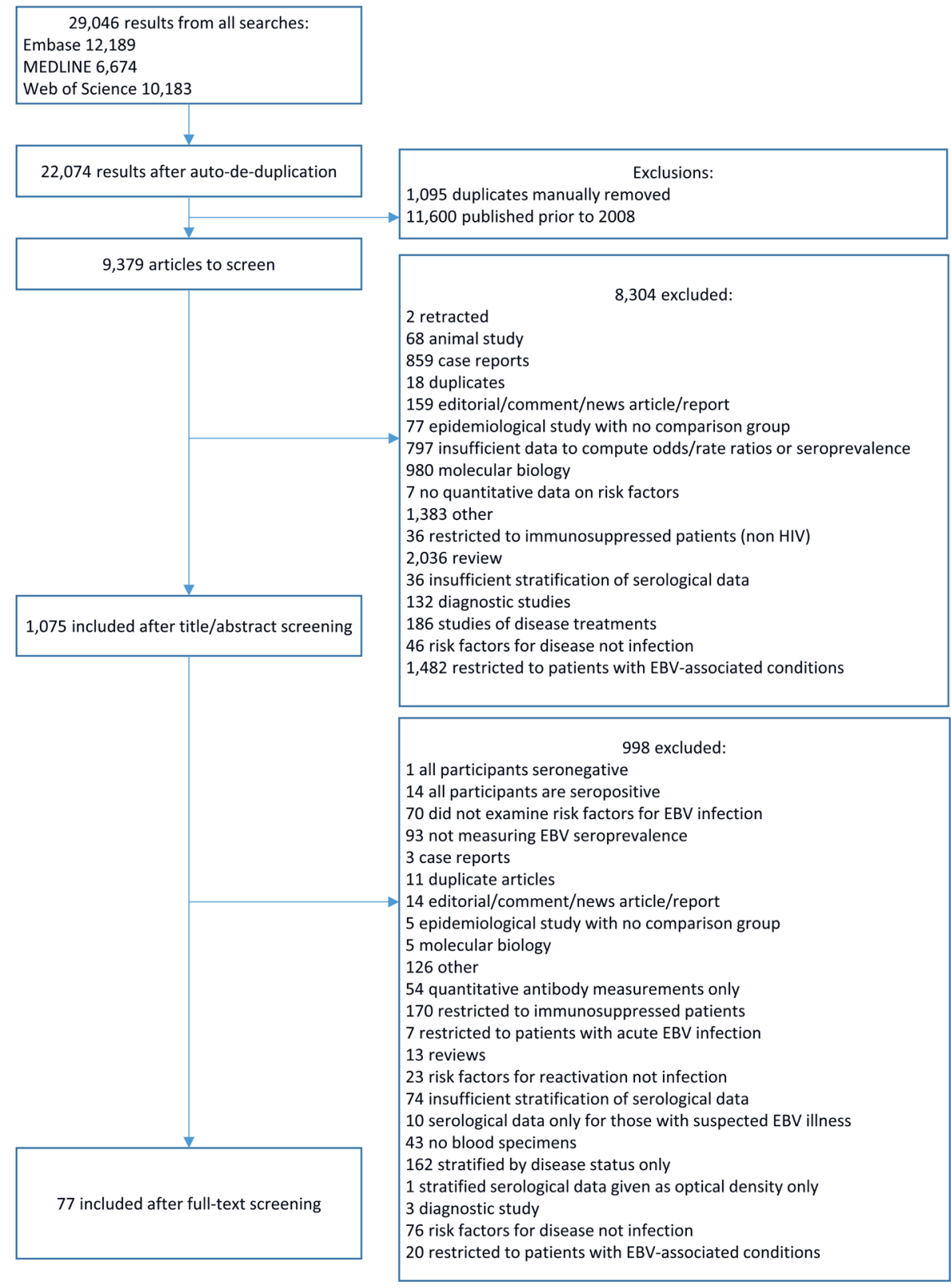

Figure 1. PRISMA flowchart of studies included in the systematic review. 


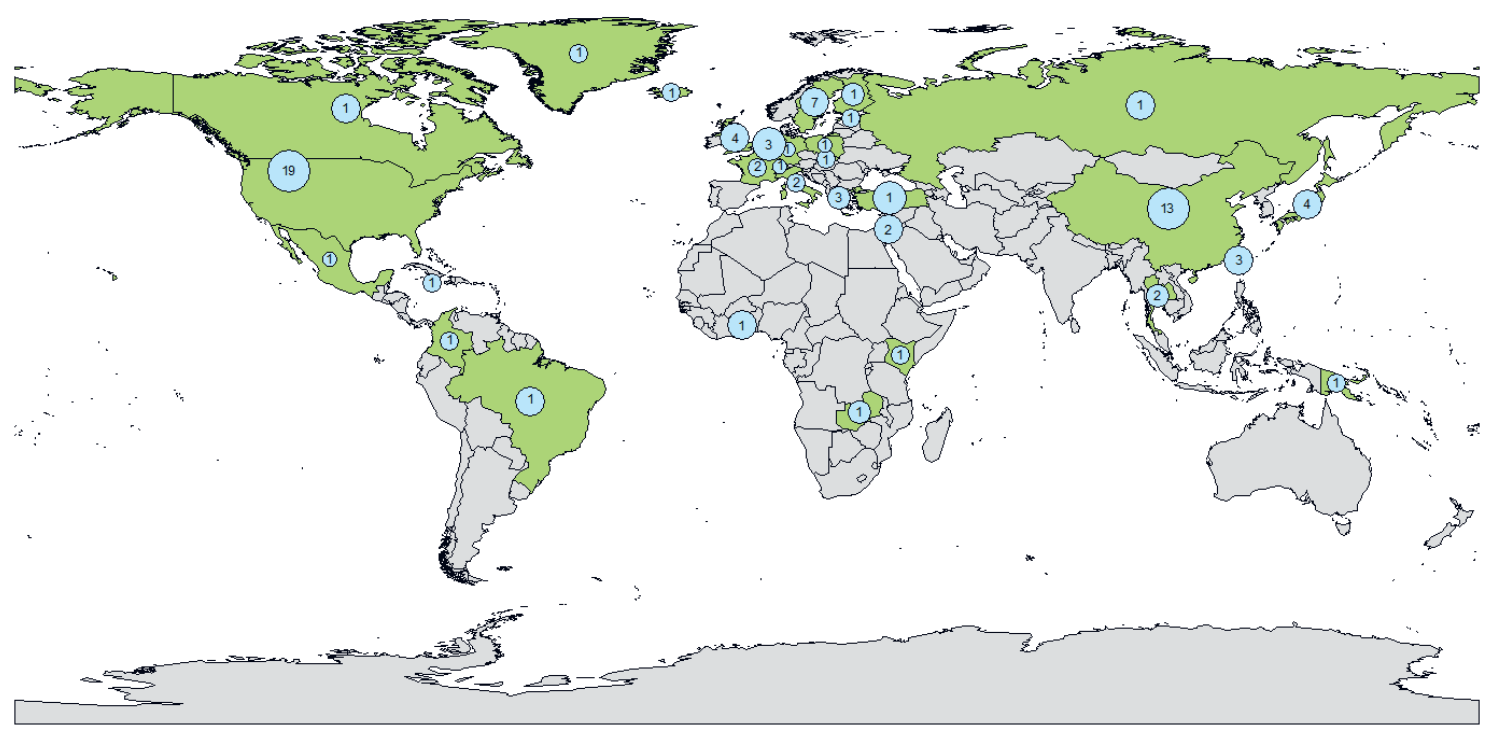

Figure 2. The global distribution of study populations included in the literature review. The size of the blue dots is proportional to the total number of individuals included in studies from each country. The number inside the dot refers to the number of studies with participants in each country.

tions such as transplant recipients $(n=7)$, those infected with the human immunodeficiency virus (HIV, $\mathrm{n}=5$ ), and others (including haemophilia and heart disease, $\mathrm{n}=17$ ).

\section{Quality assessment of included studies}

The results of our quality assessment are presented in Table S2 in the Online Supplementary Document. Thirty-eight studies examined EBV serostatus as their primary outcome and 39 as a secondary outcome. Only ten adequately adjusted for confounding, however there were no discernible differences between the results of these studies and the other studies included. Many studies lacked power; the impact of this is discussed throughout. Misclassification of serostatus may also have occurred as many studies used inhouse, unvalidated assays for detecting EBV antibodies (Table S1 in the Online Supplementary Document); these studies tended to be smaller and were less likely to satisfy other quality criteria.

\section{Age and EBV seroprevalence}

Fifty-eight studies examined age as a risk factor for EBV serostatus; the majority $(\mathrm{n}=32)$ found EBV seroprevalence increased with age (Table 1) [8,17-43,45-48]. There was a clear trend towards increasing EBV seroprevalence with age up to the age of 24 years (Figure 3), particularly when studies with $<100$ participants $(n=5)$ were excluded. Studies in older individuals ( $\geq 25$ years) showed little change in seroprevalence.

When stratifying by age and study location and restricting the analysis to studies with populations representative of the general underlying population ( $\mathrm{n}=13$ for participants $<25$ years), the data showed EBV infection occurred earlier in people in Asia than people in Europe and North America (Figure 3). In Asia EBV seroprevalence rapidly increased with age, exceeding $80 \%$ by age 5 , and $90 \%$ by $7-8$ years $[19,21,36,47]$. In contrast, studies in Europe and North America showed a more gradual increase in seroprevalence which did not exceed $90 \%$ until age 22 [23,25,28,33,38,43,49,53,79,83]. Studies which used validated, commercially available tests for EBV antigens were more likely to show increases in seroprevalence with age than studies which used in-house tests or did not reported which test they used; these studies also tended to be larger and representative of the underlying population (Table S1 in the Online Supplementary Document). Only thirteen studies fulfilled our power criteria across all age categories (Table S2 in the Online Supplementary Document); the remainder of the literature was consistent with the findings of these studies.

Most (12/16) studies that reported no association with age were of adult populations [10,53-63], suggesting that age only influences EBV seroprevalence during childhood. 
Table 1. Summary of sociodemographic and lifestyle factors associated with EBV serostatus in the literature*

\section{Risk FACTOR FOR EBV SEROSTATUS SUMmary OF RESULTS}

Seronegativity decreased with age after 6 months: 3 studies [45-47]

Seronegativity decreased with age after 18 months: 1 study [48]

No association (children included): 4 studies [49-52]

No association (all/vast majority adults): 12 studies [10,53-63]

Sex/gender $\quad$ Women were more likely to be seronegative: 8 studies [22,49,57,59,62,64-66]

Men were more likely to be seronegative: 6 studies [18,30,32,34,50,51]

No association in children, but adult women were less likely to be seronegative: 1 study [26]

Differences by sex interacted with marital status: 1 study [67]

No association: 20 studies [8,17,19,20,23,29,42-44,54-56,60,61,63,68-72]

Ethnicity

Seroprevalence was lower for white participants than those of other ethnicities: 3 studies [20,43,71]

EBV seronegativity was higher in people of Han ethnicity than other Chinese ethnicities: 1 study [57]

No association: 7 studies [31,34,53,69,73-75]

Year of participation in study No association: 2 studies [28,76]

Country of study $\quad$ No difference between Japan and Jamaica: 1 study [77]

Higher EBV seroprevalence in Mexico than Papua New Guinea, Columbia, Italy, Netherlands and Israel: 1 study [78]

Place of birth

EBV seronegativity was higher in central/Eastern China than Western China: 1 study [57]

EBV seronegativity was higher among people of European/North American origin than other world regions: 2 studies [10,79]

No association: 5 studies [19,20,36,37,55]

Socioeconomic status (SES) EBV seronegativity was associated with higher SES: 1 study [10]

No association between EBV and SES: 1 study [73]

No association with occupational/social class: 3 studies $[57,60,69]$

Higher household income was associated with EBV seronegativity: 2 studies [43,71]

No association with household income: 1 study [20]

EBV seronegativity was associated with having medical insurance for non-white participants: 1 study [43]

No association with having private medical insurance: 1 study [75]

Level of education $\quad$ Seronegativity increased with higher levels of education: 5 studies $[10,19,20,43,57]$

No association with level of education of study participant: 2 studies [34,75]

EBV seronegativity was higher among those whose parents had been in education for longer: 2 studies [10,71]

No association with parental education: 1 study [8]

Anthroposophic lifestyle

Urban/rural setting

No association: 1 study [24]

EBV seronegativity lower in urban areas than rural areas: 1 study [10]

No association: 1 study [21]

\section{Household size/structure $\quad$ Number of siblings}

EBV seroprevalence increased with number of siblings: 3 studies [10,66,71]

No association between number of siblings and EBV seropositivity: 2 studies [8,55]

\section{Birth order}

No association with birth order: 2 studies $[25,55]$

\section{Number of people in household}

Adults with more children in the house were more likely to be EBV seropositive: 1 study [69]

No association between number of adults in the house and EBV serostatus: 1 study [69]

EBV seroprevalence increased with household size: 1 study [79]

No association with household size: 1 study [53]

\begin{tabular}{l} 
Crowding of home \\
\hline Housing type (flat/house) \\
\hline Marital status
\end{tabular}

Marital status

Sexual behaviour

Smoking status
No association: 4 studies $[20,25,43,69]$

No association: 1 study [66]

EBV seronegativity higher in unmarried women than married women, but lower in unmarried men than married men: 1 study [67]

No association: 3 studies [19,53,57]

EBV seroconversion was associated with deep kissing: 1 study [55]

\section{Smoking}

Smoking associated with EBV seropositivity: 3 studies [10,39,79]

Increased association with greater exposure: 1 study [39]

No association: 6 studies [19,56,60,61,64,75]

\section{Passive smoking}

Mother smoking associated with lower EBV seronegativity: 1 study [66]

No association: 1 study [25]

Weight/body mass index

(BMI)

Increased BMI was associated with lower rates of seroprevalence: 4 studies [64,79-81]

No association: 2 studies [71,75] 
Table 1. Continued

\section{Risk factor For EBV SEROStatus Summary OF RESULIS}

\section{General dietary factors}

No association with diet: 1 study [55]

No association with eating sufficient food: 1 study [82]

No association with eating balanced meals: 1 study [82]

No association with a reliance on low-cost food: 1 study [82]

\section{Specific foods}

No association with salted fish consumption: 3 studies [39,56,61]

No association with frequency of fruit and vegetable consumption: 2 studies [56,82]

No association with frequency of eating leafy salad: 1 study [82]

No association with frequency of eating wholegrain bread: 1 study [82]

No association with frequency of eating beans: 1 study [82]

No association with frequency of eating red meat: 1 study [82]

No association with betel nut consumption: 1 study [56]

No association with slow-cooked soup consumption: 1 study [39]

No association with preserved vegetable consumption: 1 study [39]

\section{Specific drinks}

No association with frequency of drinking milk: 1 study [82]

No association with frequency of drinking juice: 1 study [82]

No association with tea consumption: 1 study [39]

No association with herbal tea consumption: 2 study [39]

\section{Alcohol consumption \\ Formaldehyde/solvent} exposure

Exercise

Height

Birth factors (baby)
No association: 3 studies $[19,39,56]$

No association: 1 study [56]

No association: 1 study [55]

No association: 2 studies [60,64]

Vaginal vs caesarean delivery

No association: 3 studies $[25,66,71]$

\section{Premature birth}

No association: 3 studies $[25,66,71]$

\section{Birth weight}

No association: 3 studies [8,66,71]

\section{Maternal characteristics}

\section{Maternal parity}

No association: 1 study [53]

\section{Maternal age}

No association: 2 studies [8,71]

\section{Maternal smoking/alcohol use during pregnancy}

No association: 1 study [71]

\section{Maternal BMI prior to pregnancy}

No association: 1 study [71]

\section{Maternal fever during third trimester}

No association: 1 study [71]

\section{Stress}

No association with stress: 1 study [55]

No association with parental stress: 1 study [25]

Attended daycare

\section{Attendance}

Attending daycare was associated with higher EBV seropositivity: 1 study [66]

No association: 2 studies [20,71]

\section{Age of starting daycare}

Daycare attendance at a younger age was associated with greater EBV seropositivity: 1 study [25]

No association: 1 study [66]

Hygiene practices No association with frequency of house cleaning: 1 study [25]

No association with frequency of handwashing: 1 study [25]

No association with having pets in the house: 2 studies $[25,66]$

Swimming

Duration of watching

television

No association with attending a swimming pool: 1 study [25]

No association with daily duration of watching television: 1 study [25]

*Adjusted results are presented where they were available, otherwise unadjusted associations are reported. There was some overlap in the data used by five studies based on data from the US National Health and Nutrition Examination Surveys $[43,76,79,82,83]$. To avoid over-representing the findings from this population, for each risk factor we have only included the findings of the largest study in this table. 
(a) EBV seroprevalence by age, up to 24 years

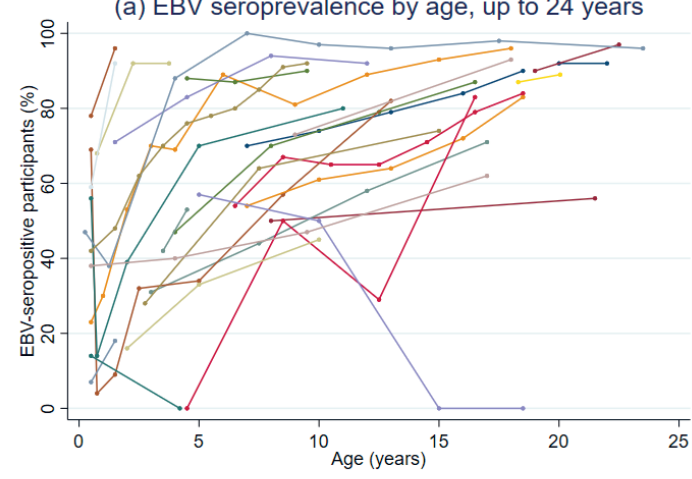

(c) EBV seroprevalence by age,

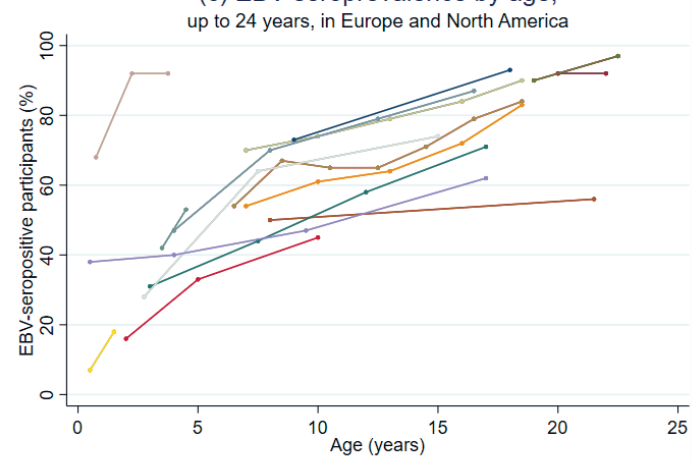

(e) EBV seroprevalence in the general population

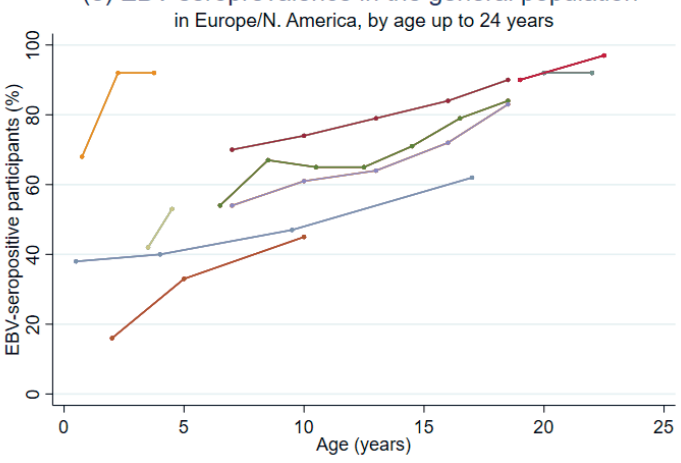

(b) EBV seroprevalence by age, over 24 years

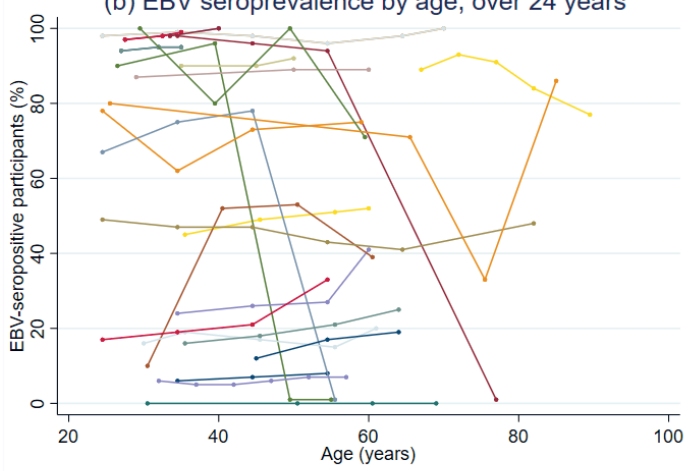

(d) EBV seroprevalence by age,

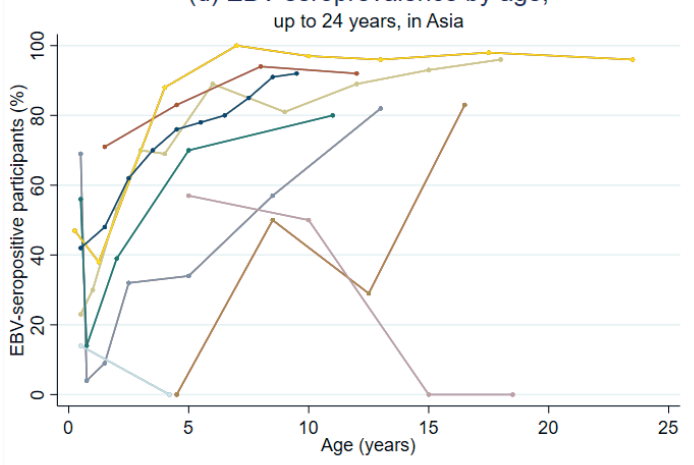

(f) EBV seroprevalence in the general population in Asia,

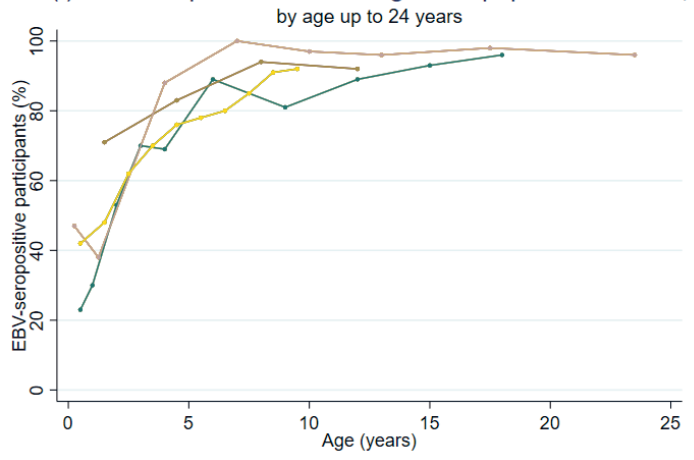

Figure 3. EBV seroprevalence by age in studies identified from the literature. Panel A. In participants up to 24 years of age. Panel B. In participants over 24 years of age. Panel C. In participants up to 24 years of age in Europe and North America. Panel D. In participants up to 24 years of age in Asia. Panel E. In participants up to 24 years of age in studies representative of their underlying populations in Europe and North America, (f) in participants up to 24 years of age in studies representative of their underlying populations in Europe and North America. Seroprevalence data categorised by age group was extracted from the literature and data points were plotted at the midpoint of each age group. Studies with only one data point above or below 24 years were excluded from the relevant graph. Studies were considered generalisable to the underlying population if it was a random sample of healthy individuals and the study population was representative of the local population.

\section{Other sociodemographic factors and EBV seroprevalence}

The majority of studies (19/36) reported no association between sex and EBV serostatus (Table 1) $[8,17,19,20,23,29,42,43,54-56,60,61,63,68-72]$. Studies which reported associations $[18,22,26,30,32,34,49-51,57,59,62,64-67]$ were evenly split in their findings, with no discernible differences according to study type, population or location, although they were generally small and lacking in power; $9 / 15$ had $\leq 75$ participants.

Relatively few studies ( $\mathrm{n}=11$ ) compared EBV seroprevalence between participants of different ethnicities or countries of birth. The majority found no association [31,34,53,69,73-75], but three reported seroprevalence was lower among white participants than other ethnicities $[20,43,71]$. 
Multiple studies investigated associations between socioeconomic status and EBV seropositivity (Table 1). Five reported no association $[20,57,60,69,73]$, whereas eight showed that EBV seropositivity was lower in people with higher levels of education $[10,19,20,43,57]$, higher socioeconomic status [10], social class or household income [43,71]. All the studies reporting an association between lower EBV prevalence and higher socioeconomic status examined young people ( $\leq 21$ years), whereas those that found no association examined all ages.

There was mixed evidence regarding an association with household size or daycare attendance (Table 1). Crowding of the home was not associated with EBV $[20,25,43,69]$. These findings did not differ by study size, design, location or population. Four studies found that smoking or passive smoking was associated with higher EBV seroprevalence [10,39,66,79]; one study reported a dose-response effect [39]. However, a further six studies reported no association $[19,56,60,61,64,75]$. Again, there were no discernible design differences between studies (Table S1 in the Online Supplementary Document).

Four of six studies reported that seroprevalence was higher among those who were overweight/obese than people of a healthy weight for older children and adults [64,79-81], whilst two studies of very young children and elderly women with physical difficulties reported no association $[71,75]$. Dietary factors were generally not associated with EBV seroprevalence (Table 1), nor were frequency of handwashing, house cleaning, or having pets in the house (Table 1).

\section{Viral and immune factors associated with EBV seroprevalence}

Thirteen studies reported data on the correlation between EBV and CMV seroprevalence (Table 2); ten reported a positive association [31,35,48,60,66,83-87]; however studies which reported a negative association or no association tended to lack power $[62,88]$.

Table 2. Summary of viral and clinical factors associated with EBV serostatus in the literature

\begin{tabular}{|c|c|}
\hline Risk Factor For EBV serostatus & SUMMARY OF RESULTS \\
\hline \multirow{3}{*}{ CMV infection } & Positive correlation between EBV and CMV serostatus: 10 studies [31,35,48,60,66,83-87] \\
\hline & Negative association: 1 study [62] \\
\hline & No association: 2 studies $[88,89]$ \\
\hline KSHV infection & Positive correlation between EBV and KSHV: 1 study [41] \\
\hline HTLV infection & Positive correlation between EBV and HTLV serostatus: 1 study [77] \\
\hline HSV-1 infection & Positive correlation between EBV and HSV-1 serostatus: 1 study [83] \\
\hline Toxoplasmosis infection & No association: 1 study [89] \\
\hline Rubella infection & No association: 1 study [89] \\
\hline Syphilis & No association: 1 study [89] \\
\hline Anti-IFN-gamma autoantibodies & No association: 1 study [89] \\
\hline \multirow{8}{*}{ HIV infection } & HIV infection \\
\hline & Positive correlation between EBV and HIV status: 2 studies $[8,17]$ \\
\hline & No association: 1 study [90] \\
\hline & CD4 count \\
\hline & No association: 2 studies $[54,57]$ \\
\hline & Mother's low CD4 percentage was associated with EBV seropositivity: 1 study [8] \\
\hline & Viral load \\
\hline & Mother's higher viral load was associated with being EBV seropositive: 1 study [8] \\
\hline \multirow{2}{*}{ Sensitised to IgE (allergy testing) } & EBV-seronegative individuals had higher odds of $\geq 1$ positive specific IgE test: 1 study [52] \\
\hline & No association: 1 study [24] \\
\hline Maternal family history of atopy & No association: 1 study [71] \\
\hline Positive skin prick tests & EBV-seronegative individuals had higher odds of $\geq 1$ skin prick test: 1 study [52] \\
\hline \multirow{4}{*}{ Breastfed } & Breastfeeding \\
\hline & No association: 1 study [20] \\
\hline & Duration of being breastfed \\
\hline & No association with duration of being breastfed: 4 studies $[8,25,66,71]$ \\
\hline $\begin{array}{l}\text { Respiratory or gastrointestinal } \\
\text { tract infections in first year of life }\end{array}$ & No association: 1 study [71] \\
\hline History of tonsillectomy & More common among EBV seronegative individuals: 1 study [73] \\
\hline
\end{tabular}


EBV seropositivity was also associated with infection with Kaposi's sarcoma-associated herpesvirus (KSHV) [41], human T-cell lymphotropic virus (HTLV) [77], herpes simplex virus-1 (HSV-1) [83] and HIV [8,17]. CD4 count was not associated with EBV status in study participants with HIV (Table 2) [54,57], however, EBV seroprevalence was higher among infants whose mothers had HIV and were immunosuppressed [8].

There was some evidence of an association between EBV seroprevalence and positive allergy tests (Table 2) [52], although other studies found no association with positive allergy tests or atopy [24,71]. Prior tonsillectomy was less common among those who were EBV seropositive [73]. There was no association with having been breastfed [20], duration of breastfeeding [8,25,66,71], or having other gastrointestinal or respiratory tract infections during the first year of life [71].

\section{Genetic factors associated with EBV seronegativity}

Three studies examined associations between immune system genes and EBV serostatus (Table 3). We refer here to associations with seronegativity, rather than seropositivity, as these are the genetic differences relevant to vaccination. Polymorphisms in the mannose-binding lectin gene [24], but not the defensin beta 1 gene [64], were associated with EBV seronegativity in children. Polymorphisms regulating the function of HLA-Bw4 and HLA-C were associated with EBV seronegativity in a cohort of healthy people aged $>60$ years [73]. Two other studies reported associations between gene polymorphisms and the EBV-specific antibody response in people that acquired the virus. None of these studies made adequate adjustments for confounding and their findings have not been replicated.

Table 3. Summary of human genetic factors associated with EBV serostatus in the literature

\begin{tabular}{|c|c|}
\hline $\begin{array}{l}\text { Risk Factor FOR } \\
\text { EBV SEROSTATUS }\end{array}$ & SUMMARY Of RESULTS \\
\hline \multirow{4}{*}{$\begin{array}{l}\text { Immunological } \\
\text { markers }\end{array}$} & HLA-C variant with the presence of TT at position -35 was more common in EBV seropositive individuals: 1 study [73] \\
\hline & Frequency of HLA-Bw4 epitopes was lower in EBV seronegative individuals: 1 study [73] \\
\hline & MBL-insufficient genotype (vs MBL-sufficient genotype) was associated with higher rates of EBV seronegativity: 1 study [23] \\
\hline & No association between haplotype of the $\beta$-defensin- 1 gene (DEFB1) and EBV seroprevalence: 1 study [91] \\
\hline
\end{tabular}

EBV - Epstein-Barr virus, C - cytosine, HLA - human leukocyte antigen, IL - interleukin. MBL - mannose-binding lectin, $\mathrm{T}$ - thymine

\section{DISCUSSION}

Our systematic review of the literature is, to our knowledge, the first to summarise global risk factors for EBV infection whilst simultaneously assessing the quality of studies using a standardised tool. This formal assessment of the epidemiological evidence is critical to provide a comprehensive summary of the current evidence base to inform the direction of future research and policy, and to identify gaps that exist in the literature either because of a total absence of research, or an abundance of poor-quality research. Increasing age and co-infection with CMV were strongly associated with higher EBV seroprevalence. Critically, infection with EBV occurred at a younger age in study populations in Asia than in Europe or North America. Additionally, socioeconomic status, household size, smoking, body mass index (BMI), co-infections and genetic variants of immunological genes were associated with EBV serostatus, with varying degrees of certainty.

The age at which EBV infection occurs is an essential consideration when designing infection-preventing vaccination strategies. Variability in the age at infection between countries and settings will be a critical factor in deciding if, when, and how to roll out infection-preventing EBV vaccines in order to ensure cost-effectiveness, and whether or not a vaccine is cost-effective may differ between settings. Our literature review demonstrated that in Asian populations, where seroprevalence reached $80 \%$ by age 5 , vaccinating infants would be essential to prevent infection. In contrast, in Europe and North America seroprevalence increases more gradually throughout childhood and adolescence, and the burden of IM is higher [3]. A vaccine like the original gp350-based based vaccine [92], which was unable to prevent infection but reduced IM incidence, could be deployed in these populations. Debilitating in its own right, IM is also associated with increased risk of developing EBV-positive Hodgkin's lymphoma (HL) and multiple sclerosis (MS) [93,94], accordingly, a vaccine capable of reducing IM should decrease inci- 
dence of both conditions over time. A vaccine capable of preventing EBV infection from occurring could potentially have a much greater impact; reducing not only the incidence of HL but also of other malignancies where EBV infection is necessary for pathogenesis, but IM has not been reported to increase the risk. In addition to cancers, a history of IM is also associated with an elevated risk of multiple sclerosis; an IM-preventing vaccine could therefore potentially reduce the risk of this common autoimmune disease. However, a much greater effect might be achieved by a fully protective EBV vaccine, since the relative risk of MS development in EBV seronegative individuals is substantially lower than that of those carrying the virus [95]. Multiple lines of evidence support a causal role for EBV in MS [95]. If EBV infection is truly a pre-requisite for MS development then there is, in principle, no reason why a vaccine that prevents EBV infection would not prevent MS.

Importantly, incomplete vaccine coverage or imperfect efficacy could also increase the average age of EBV acquisition by reducing the pool of susceptible individuals, but not enough to prevent transmission; potentially increasing the likelihood of EBV-infection associated sequelae such as IM. Vaccination against Varicella Zoster virus (the only herpesvirus currently preventable by vaccination) is not recommended unless high vaccine coverage can be achieved, because increasing the average age of infection results in greater severity of disease [96]. The impact of age at EBV infection on the incidence of EBV-associated cancers is relatively unknown. For an EBV vaccination program to prevent EBV-associated cancers, vaccination policies will also be dependent on the rates of EBV-associated cancers in different settings, and the age at which these cancers typically occur.

There is a considerable lack of data on EBV seroprevalence by age in Africa and South America, and many studies from Asia were not generalisable to the wider population, thus limiting their usefulness for vaccination planning. High-quality, setting-specific data on the age at which EBV infection is acquired are essential for understanding EBV epidemiology in different settings and informing effective local vaccination policies. Future work is also required to understand why some individuals remain EBV seronegative for life, and the implications of this, which has important implications before implementing any vaccination strategy.

Many sociodemographic risk factors have been associated with EBV infection, however the causality of these relationships is difficult to determine for two broad reasons. First, socioeconomic status (SES) is a complex and dynamic measure that reflects different levels of exposure to multiple environmental and lifestyle factors. Second, lower SES is linked to diverse multiple biological factors that include chronic stress, increased pro-inflammatory immune factors [97], lower overall immunity and potentially shorter telomere length [98], although the causal nature of these relationships are not understood. Many of these factors could conceivably alter susceptibility to EBV infection and the risk of EBV infection occurring at a younger age. Dedicated studies exploring a wide range of sociodemographic and lifestyle factors within whole families are therefore needed to understand the causal factors leading to EBV infection in more detail, and these factors are likely to vary in different settings. Based on the current data it is, however, possible to make three general conclusions. First, the evidence showing SES was associated with EBV seroprevalence in studies of young people, but not in studies that included adults older than 21 years, suggests that SES is associated with the age at which EBV infection is acquired, but not with whether individuals remain uninfected for life. Thus, SES may have important effects on EBV-associated disease by mediating the age at which individuals are infected; it is known that EBV infection during adolescence frequently causes IM. Second, risk factors relating to SES which may directly influence the risk of EBV transmission (such as household size and crowding) were not found to be associated with EBV serostatus in our review, although it is possible they may be associated with the age of infection, which we were not able to explore. Finally, the mixed evidence as to whether there is an association between smoking and EBV suggests that this could be due to the association with socioeconomic status, rather than smoking being an independent risk factor. Similarly, higher income and/or social class, or higher BMI are likely confounders for other causal factors, rather than having an independent effect. However, what these causal factors may be remains unclear.

A meta-analysis of the association between EBV seroprevalence and latitude (of the studies, not individual participants) reported that EBV seroprevalence increased with distance from the equator, and suggested that as well as genetic, social and climactic factors, vitamin D may have a role in EBV-associated disease [99]. We did not identify any studies which looked at the association between vitamin D and EBV seroprevalence; this may merit further investigation. 
There was a consistently positive association between infection with EBV and CMV, however we were unable to determine the temporality of this relationship, as no studies found in the literature have examined whether one infection preceded the other. The association may result from shared genetic, immunological and/or sociodemographic risk factors, or one infection could increase susceptibility to the other. Longitudinal studies with serial testing are necessary to explore this association in more detail. We note that a variety of antibodies were used to measure seroprevalence across the different studies, providing an additional degree of heterogeneity. Although IgG is the most utilised as an indicator of antibody-based immunity some studies also measured IgM (early-stage humoral immunity) and/or IgA (found in mucosal areas; IgA anti-VCA is more associated with nasopharyngeal carcinoma patients).

While multiple studies have studied links between genes involved in antiviral immunity and EBV-related disease [2], we identified only three studies examining links between such genes and EBV serostatus within the time period of our inclusion criteria. This small number of studies may be a consequence of the low frequency of EBV seronegative individuals in the adult population meaning large cohorts are required to identify sufficient EBV seronegative donors to produce robust conclusions. All three genes identified as being associated with EBV serostatus (mannose-binding lectin, HLA-Bw4 and HLA-C) are involved in the innate immune system; and older, smaller studies have reported similar associations [100102]. Further studies are needed to determine the mechanisms by which these polymorphisms are associated with a lack of EBV infection, and whether other genes are similarly associated with EBV serostatus.

The comprehensive search strategy for the systematic review was designed to be highly sensitive, and we included papers in any language to ensure our results were comprehensive. Heterogeneity in study design in the existing literature, and wide variation in the risk factors reported, meant that a formal meta-analysis of our findings was not appropriate.

Confounding made it difficult to compare studies as there was substantial variation in the factors each paper adjusted for, and many studies only reported univariable results. However, this did not appear to cause systematic bias in the results. An important contribution of this study is that it will enable future studies to be better informed regarding the confounders they need to control for in their analyses in order to ensure unbiased estimates of effect sizes for other risk factors. The majority of studies were cross-sectional, meaning that the temporality of associations could not be assessed. As EBV infection is often acquired a young age, it may have preceded the reported risk factors, particularly factors such as BMI, smoking and diet. It is unclear whether high BMI is a risk factor for EBV infection, whether EBV infection predisposes individuals to obesity, or whether BMI is a confounder for other factors causally associated with EBV. The majority of the studies we found were conducted in Europe, North America and Southeast Asia, therefore our findings may not be generalisable outside these settings.

\section{CONCLUSIONS}

In this systematic review we document the diverse factors that have been analysed globally for potential associations with EBV seroprevalence, provide a formal assessment of the quality of studies, and discuss the implications for future vaccine policy. EBV seroprevalence generally increases until around 24 years of age and remains constant thereafter; however infection is acquired earlier in Asia than in Europe and North America. Consequently, depending upon the efficacy and duration of protection of a vaccine, different vaccination strategies may be required in different settings. In Asia, vaccination of infants would be required to prevent EBV infection from occurring. In contrast, in Western countries a vaccine with limited duration of protection could prevent IM in older seronegative individuals, thereby reducing EBV-associated disease. There is a lack of high-quality data on the prevalence and age of EBV infection outside of Europe, North America and South-East Asia, which will be essential for informing effective vaccination policies in these settings. 


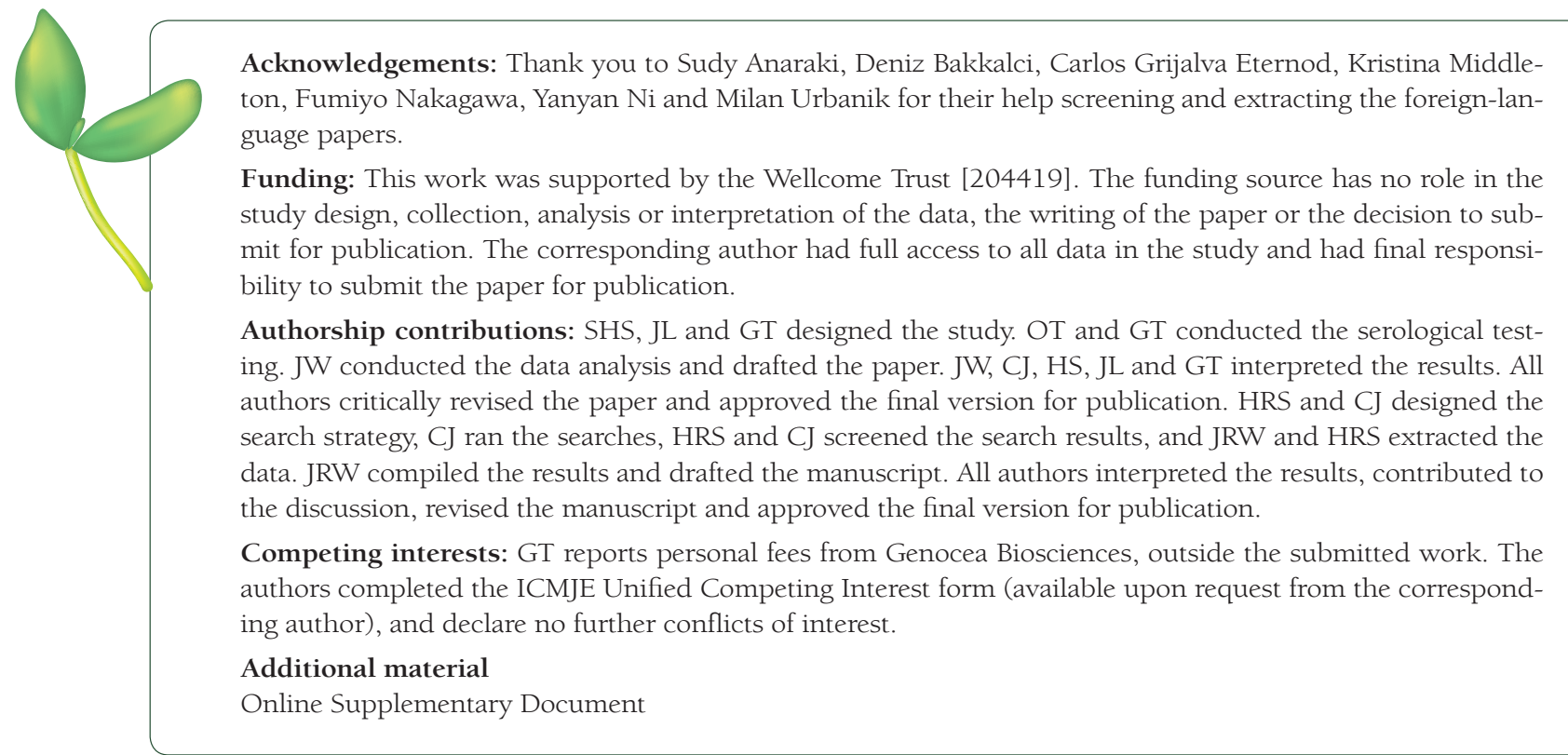

1 Chang CM, Yu KJ, Mbulaiteye SM, Hildesheim A, Bhatia K. The extent of genetic diversity of Epstein-Barr virus and its geographic and disease patterns: a need for reappraisal. Virus Res. 2009;143:209-21. Medline:19596032 doi:10.1016/j. virusres.2009.07.005

2 Houldcroft CJ, Kellam P. Host genetics of Epstein-Barr virus infection, latency and disease. Rev Med Virol. 2015;25:7184. Medline:25430668 doi:10.1002/rmv. 1816

3 Evans AS. Infectious mononucleosis and related syndromes. Am J Med Sci. 1978;276:325-39. Medline:217270 doi:10.1097/00000441-197811000-00010

4 Parkin DM. The global health burden of infection-associated cancers in the year 2002. Int J Cancer. 2006;118:3030-44. Medline:16404738 doi:10.1002/ijc.21731

5 Cohen JI, Fauci AS, Varmus H, Nabel GJ. Epstein-Barr virus: an important vaccine target for cancer prevention. Sci Transl Med. 2011;3:107fs7. Medline:22049067 doi:10.1126/scitranslmed.3002878

6 Cohen JI. Vaccine Development for Epstein-Barr Virus. Adv Exp Med Biol. 2018;1045:477-93. Medline:29896681 doi:10.1007/978-981-10-7230-7_22

7 Piriou E, Asito AS, Sumba PO, Fiore N, Middeldorp JM, Moormann AM, et al. Early age at time of primary Epstein-Barr virus infection results in poorly controlled viral infection in infants from Western Kenya: clues to the etiology of endemic Burkitt lymphoma. J Infect Dis. 2012;205:906-13. Medline:22301635 doi:10.1093/infdis/jir872

8 Slyker JA, Casper C, Tapia K, Richardson B, Bunts L, Huang ML, et al. Clinical and virologic manifestations of primary Epstein-Barr virus (EBV) infection in Kenyan infants born to HIV-infected women. J Infect Dis. 2013;207:1798-806. Medline:23493724 doi:10.1093/infdis/jit093

9 Hjalgrim H, Friborg J, Melbye M. Chapter 53. The epidemiology of EBV and its association with malignant disease. In: Arvin A, Campadelli-Fiume G, Mocarski E, al. e, editors. Human herpesviruses: Biology, Therapy and Immunoprophylaxis. Cambridge: Cambridge University Press; 2007.

10 Levine H, Balicer RD, Rozhavski V, Halperin T, Shreberk M, Davidovitch N, et al. Seroepidemiology of Epstein-Barr virus and cytomegalovirus among Israeli male young adults. Ann Epidemiol. 2012;22:783-8. Medline:22831994 doi:10.1016/j. annepidem.2012.06.099

11 Lazda VA. Evaluation of Epstein-Barr virus (EBV) antibody screening of organ donors for allocation of organs to EBV serostatus matched recipients. Transplant Proc. 2006;38:3404-5. Medline:17175286 doi:10.1016/j.transproceed.2006.10.066

12 Simanek AM, Dowd JB, Pawelec G, Melzer D, Dutta A, Aiello AE. Seropositivity to cytomegalovirus, inflammation, allcause and cardiovascular disease-related mortality in the United States. PLoS One. 2011;6:e16103. Medline:21379581 doi:10.1371/journal.pone.0016103

13 Ehlers B, Spiess K, Leendertz F, Peeters M, Boesch C, Gatherer D, et al. Lymphocryptovirus phylogeny and the origins of Epstein-Barr virus. J Gen Virol. 2010;91:630-42. Medline:19923263 doi:10.1099/vir.0.017251-0

14 Leendertz FH, Deckers M, Schempp W, Lankester F, Boesch C, Mugisha L, et al. Novel cytomegaloviruses in free-ranging and captive great apes: phylogenetic evidence for bidirectional horizontal transmission. J Gen Virol. 2009;90:2386-94. Medline:19553394 doi:10.1099/vir.0.011866-0

15 Downs SH, Black N. The feasibility of creating a checklist for the assessment of the methodological quality both of randomised and non-randomised studies of health care interventions. J Epidemiol Community Health. 1998;52:377-84. Medline:9764259 doi:10.1136/jech.52.6.377 
16 Deeks JJ, Dinnes J, D’Amico R, Sowden AJ, Sakarovitch C, Song F, et al. Evaluating non-randomised intervention studies. Health Technol Assess. 2003; 7:iii-x, 1-173. Medline:14499048 doi:10.3310/hta7270

17 Adjei AA, Armah HB, Gbagbo F, Boamah I, Adu-Gyamfi C, Asare I. Seroprevalence of HHV-8, CMV, and EBV among the general population in Ghana, West Africa. BMC Infect Dis. 2008;8:111. Medline:18706107 doi:10.1186/1471-2334-8-111

18 Bian X, Wallstrom G, Davis A, Wang J, Park J, Throop A, et al. Immunoproteomic profiling of antiviral antibodies in new-onset type 1 diabetes using protein arrays. Diabetes. 2016;65:285-96. Medline:26450993

19 Chen CY, Huang KY, Shen JH, Tsao KC, Huang YC. A large-scale seroprevalence of Epstein-Barr virus in Taiwan. PLoS One. 2015;10:e0115836. Medline:25615611 doi:10.1371/journal.pone.0115836

20 Condon LM, Cederberg LE, Rabinovitch MD, Liebo RV, Go JC, Delaney AS, et al. Age-specific prevalence of Epstein-Barr virus infection among Minnesota children: effects of race/ethnicity and family environment. Clin Infect Dis. 2014;59:5018. Medline:24820696 doi:10.1093/cid/ciu342

$21 \mathrm{Du}$ HJ, Zhou L, Liu HT, Wang Q, Zhan SB, Jia ZY, et al. A serological survey of Epstein-Barr virus infection in children in Beijing. Zhonghua Shi Yan He Lin Chuang Bing Du Xue Za Zhi. 2008;22:30-2. Medline:18414694

22 Du JL, Chen SH, Huang QH, Xie SH, Ye YF, Gao R, et al. Subtype distribution and long-term titer fluctuation patterns of serum anti-Epstein-Barr virus antibodies in a non-nasopharyngeal carcinoma population from an endemic area in South China: a cohort study. Chin J Cancer. 2016;35:78. Medline:27527073 doi:10.1186/s40880-016-0130-2

23 Friborg JT, Jarrett RF, Koch A, Garred P, Freeland JML, Andersen A, et al. Mannose-binding lectin genotypes and susceptibility to epstein-barr virus infection in infancy. Clin Vaccine Immunol. 2010;17:1484-7. Medline:20610664 doi:10.1128/ CVI.00527-09

24 Hesla HM, Gutzeit C, Stenius F, Scheynius A, Dahl H, Linde A, et al. Herpesvirus infections and allergic sensitization in children of families with anthroposophic and non-anthroposophic lifestyle - the ALADDIN birth cohort. Pediatr Allergy Immunol. 2013;24:61-5. Medline:23331530 doi:10.1111/pai.12030

25 Karachaliou M, Waterboer T, Casabonne D, Chalkiadaki G, Roumeliotaki T, Michel A, et al. The natural history of human polyomaviruses and herpesviruses in early life - The rhea birth cohort in Greece. Am J Epidemiol. 2016;183:6719. Medline:26968942 doi:10.1093/aje/kwv281

26 Karadag A, Yanik K, Usta E, Gunduz M, Eroglu C, Gunaydin M. Seropositivity of Epstein-Barr virus (EBV) infection in children and adults and evaluation in terms of the years. Acta Medica Mediterranea. 2014;30:1215-9.

27 Kucharska M, Inglot M, Szymczak A, Rymer W, Zalewska M, Malyszczak K, et al. Co-infection of the hepatitis C virus with other blood-borne and hepatotropic viruses among hemophilia patients in Poland. Hepat Mon. 2016;16:e35658. Medline:27822257 doi:10.5812/hepatmon.35658

28 Puhakka L, Sarvikivi E, Lappalainen M, Surcel HM, Saxen H. Decrease in seroprevalence for herpesviruses among pregnant women in Finland: Cross-sectional study of three time points 1992, 2002 and 2012. Infect Dis (Lond). 2016;48:40610. Medline:26654892 doi:10.3109/23744235.2015.1123290

29 Qin HD, Jia WH, Zhang LL, Liu N, Zhou XX, Wang MH, et al. Elevated Epstein-Barr virus seroreactivity among unaffected members of families with nasopharyngeal carcinoma. J Med Virol. 2011;83:1792-8. Medline:21837797 doi:10.1002/ jmv.22121

30 Ritter J, Seitz V, Balzer H, Gary R, Lenze D, Moi S, et al. Donor CD4 T cell diversity determines virus reactivation in patients after hla-matched allogeneic stem cell transplantation. Am J Transplant. 2015;15:2170-9. Medline:25873100 doi:10.1111/ajt.13241

31 Sampaio MS, Cho YW, Shah T, Bunnapradist S, Hutchinson IV. Impact of EpsteinBarr virus donor and recipient serostatus on the incidence of post-transplant lymphoproliferative disorder in kidney transplant recipients. Nephrol Dial Transplant. 2012;27:2971-9. Medline:22273720 doi:10.1093/ndt/gfr769

32 Sato T, Fujieda M, Maeda A, Tanaka E, Miyamura M, Chikamoto H, et al. Monitoring of Epstein-Barr virus load and killer T cells in pediatric renal transplant recipients. Clin Nephrol. 2008;70:393-403. Medline:19000539 doi:10.5414/CNP70393

33 Simon KC, Saghafian-Hedengren S, Sverremark-Ekstrom E, Nilsson C, Ascherio A. Age at Epstein-Barr virus infection and Epstein-Barr virus nuclear antigen-1 antibodies in Swedish children. Mult Scler Relat Disord. 2012;1:136-8. Medline:25877079 doi:10.1016/j.msard.2012.03.002

34 Stowe RP, Peek MK, Perez NA, Yetman DL, Cutchin MP, Goodwin JS. Herpesvirus reactivation and socioeconomic position: a community-based study. J Epidemiol Community Health. 2010;64:666-71. Medline:19825788 doi:10.1136/ jech.2008.078808

35 Sundqvist E, Bergstrom T, Daialhosein H, Nystrom M, Sundstrom P, Hillert J, et al. Cytomegalovirus seropositivity is negatively associated with multiple sclerosis. Mult Scler. 2014;20:165-73. Medline:23999606 doi:10.1177/1352458513494489

36 Xiong G, Zhang B, Huang M-y, Zhou H, Chen L-z, Feng Q-s, et al. Epstein-Barr virus (EBV) infection in Chinese children: a retrospective study of age-specific prevalence. PLoS One. 2014;9:e99857. Medline:24914816 doi:10.1371/journal.pone.0099857

37 Yi B, Gu YL, Zong YS, Cheng WM, Ji MF. Six anti-Epstein-Barr virus antibodies in healthy adults in a high risk area of nasopharyngeal carcinoma. Ai Zheng. 2009;28:822-6. Medline:19664327 doi:10.5732/cjc.009.10095

38 Zebrun AB, Kuliasheva LB, Ermolenko KD, Zakrevskaia AV. Spread of herpesvirus infections in children and adults in st. petersburg according to seroepidemiologic study data. Zh Mikrobiol Epidemiol Immunobiol. 2013;6:30-6. Medline:24605672

39 Xu FH, Xiong D, Xu YF, Cao SM, Xue WQ, Qin HD, et al. An epidemiological and molecular study of the relationship between smoking, risk of nasopharyngeal carcinoma, and epsteinbarr virus activation. J Natl Cancer Inst. 2012;104:1396410. Medline:22972969 doi:10.1093/jnci/djs320 
40 Jeziorski E, Senechal B, Molina TJ, Devez F, Leruez-Ville M, Morand P, et al. Herpes-virus infection in patients with Langerhans cell histiocytosis: a case-controlled sero-epidemiological study, and in situ analysis. PLoS One. 2008;3:e3262. Medline:18810271 doi:10.1371/journal.pone.0003262

41 Minhas V, Brayfield BP, Crabtree KL, Kankasa C, Mitchell CD, Wood C. Primary gamma-herpesviral infection in Zambian children. BMC Infect Dis. 2010;10:115. Medline:20462453 doi:10.1186/1471-2334-10-115

42 Yu X, Ji M, Yu Y, Cheng W, Wu B, Hong M. Epidemiological study of epstein-barr virus infection for nasopharyngeal carcinoma screening in high-incidence areas. [In Chinese]. Chin J Clin Oncol. 2011;38:1551-4.

43 Balfour HH Jr, Sifakis F, Sliman JA, Knight JA, Schmeling DO, Thomas W. Age-specific prevalence of Epstein-Barr virus infection among individuals aged 6-19 years in the United States and factors affecting its acquisition. J Infect Dis. 2013;208:1286-93. Medline:23868878 doi:10.1093/infdis/jit321

44 Bucková A. Prevalence of anti-Epstein-Barr virus antibodies in children and adolescents with secondary immunodeficiency. Epidemiol Mikrobiol Imunol. 2010;59:133-7. Medline:20925250

45 Fuse S, Fujinaga E, Mori T, Hotsubo T, Kuroiwa Y, Morii M. Children with Kawasaki disease are not infected with Epstein-Barr virus. Pediatr Infect Dis J. 2010;29:286-7. Medline:20190617 doi:10.1097/INF.0b013e3181c3f111

46 Liu XZ, Jiang L, Wang XM. Condition of Epstein Barr virus infection in hospitalized children from Wuhan region. [Chinese]. Zhongguo Dang Dai Er Ke Za Zhi. 2011;13:23-5. Medline:21251381

47 Suntornlohanakul R, Wanlapakorn N, Vongpunsawad S, Thongmee T, Chansaenroj J, Poovorawan Y. Seroprevalence of Anti-EBV IgG among Various Age Groups from Khon Kaen Province, Thailand. Asian Pac J Cancer Prev. 2015;16:75837. Medline:26625765 doi:10.7314/APJCP.2015.16.17.7583

48 Preiksaitis JK, Toogood K, Fenton J. Optimizing laboratory screening for epstein barr virus serostatus in solid organ transplant recipients. Transplantation. 2010;90:668. doi:10.1097/00007890-201007272-01279

49 Rodriguez TA, Fernandes KE, Dresser KL, Duvic M. Concordance rate of alopecia areata in identical twins supports both genetic and environmental factors. J Am Acad Dermatol. 2010;62:525-7. Medline:20159328 doi:10.1016/j. jaad.2009.02.006

50 Sato T, Fujieda M, Tanaka E, Miyamura M, Chikamoto H, Hisano M, et al. Monitoring of Epstein-Barr virus load and antibody in pediatric renal transplant patients. Pediatr Int. 2008;50:454-8. Medline:19143966 doi:10.1111/j.1442200X.2008.02579.x

51 Wu JF, Ho MC, Ni YH, Chen HL, Lu CY, Hsu HY, et al. Timing of epstein-barr virus acquisition and the course of posttransplantation lymphoproliferative disorder in children. Transplantation. 2009;87:758-62. Medline:19295323 doi:10.1097/ TP.0b013e318198d645

52 Alcantara-Neves NM, Veiga RV, Dattoli VC, Fiaccone RL, Esquivel R, Cruz AA, et al. The effect of single and multiple infections on atopy and wheezing in children. J Allergy Clin Immunol. 2012;129:359-67. Medline:22035877 doi:10.1016/j. jaci.2011.09.015

53 Pembrey L, Raynor P, Griffiths P, Chaytor S, Wright J, Hall AJ. Seroprevalence of cytomegalovirus, Epstein Barr virus and varicella zoster virus among pregnant women in Bradford: a cohort study. PLoS One. 2013;8:e81881. Medline:24312372 doi:10.1371/journal.pone.0081881

54 Abdollahi A, Shoar S, Rasoulinejad M, Sheikhbahaei S. Seroprevalence of Epstein-Barr virus among HIV positive patients moreover and its association with CD4 positive lymphocyte count. Acta Med Iran. 2014;52:916-21. Medline:25530055

55 Balfour HH Jr, Odumade OA, Schmeling DO, Mullan BD, Ed JA, Knight JA, et al. Behavioral, virologic, and immunologic factors associated with acquisition and severity of primary Epstein-Barr virus infection in university students. [Erratum appears in J Infect Dis. 2013 Jun 15;207(12):1940]. J Infect Dis. 2013;207:80-8. Medline:23100562 doi:10.1093/ infdis/jis646

56 Chang CM, Yu KJ, Hsu WL, Major JM, Chen JY, Lou PJ, et al. Correlates of anti-EBV EBNA1 IgA positivity among unaffected relatives from nasopharyngeal carcinoma multiplex families. Br J Cancer. 2012;106:206-9. Medline:22095229 doi:10.1038/bjc.2011.502

57 He N, Chen L, Lin H, Zhang M, Wei J, Yang J, et al. Multiple viral coinfections among HIV/AIDS patients in China. Biosci Trends. 2011;5:1-9. Medline:21422594 doi:10.5582/bst.2011.v5.1.1

58 Mousavi SSB, Hayati F. Do we need to screen our patients for EBVIgGantibody before kidney transplantation? Nephrourol Mon. 2011;3:122-4

59 Rubicz R, Leach CT, Kraig E, Dhurandhar NV, Grubbs B, Blangero J, et al. Seroprevalence of 13 common pathogens in a rapidly growing U.S. minority population: Mexican Americans from San Antonio, TX. BMC Res Notes. 2011;4:433. Medline:22018212 doi:10.1186/1756-0500-4-433

60 Savva GM, Pachnio A, Kaul B, Morgan K, Huppert FA, Brayne C, et al. Cytomegalovirus infection is associated with increased mortality in the older population. Aging Cell. 2013;12:381-7. Medline:23442093 doi:10.1111/acel.12059

61 Shen GP, Pan QH, Hong MH, Qin HD, Xu YF, Chen LZ, et al. Human genetic variants of homologous recombination repair genes first found to be associated with Epstein-Barr virus antibody titers in healthy Cantonese. Int J Cancer. 2011;129:1459-66. Medline:21792882 doi:10.1002/ijc.25759

62 Wang C, Liu Y, Xu LT, Jackson KJL, Roskin KM, Pham TD, et al. Effects of aging, cytomegalovirus infection, and EBV infection on human B cell repertoires. J Immunol. 2014;192:603-11. Medline:24337376 doi:10.4049/jimmunol.1301384

63 Thomas de Montpréville V, Le Pavec J, Le Roy Ladurie F, Crutu A, Mussot S, Fabre D, et al. Lymphoproliferative Disorders after Lung Transplantation: Clinicopathological Characterization of 16 Cases with Identification of Very-Late-Onset Forms. Respiration. 2015;90:451-9. Medline:26506523 doi:10.1159/000441064 
64 Bertrand KA, Birmann BM, Chang ET, Spiegelman D, Aster JC, Zhang SM, et al. A prospective study of Epstein-Barr virus antibodies and risk of non-Hodgkin lymphoma. Blood. 2010;116:3547-53. Medline:20647565 doi:10.1182/ blood-2010-05-282715

65 Gerakari S, Zouboulis-Vafiadis I, Chrysos G, Daikos GL, Themeli-Digalaki K, Papadopoulos S, et al. The effect of coinfection by hepatotropic and hepatomimetic viruses in physical evolution of HCV hepatitis. Int J Infect Dis. 2011;9:1-9.

66 Saghafian-Hedengren S, Sundstrom Y, Sohlberg E, Nilsson C, Linde A, Troye-Blomberg M, et al. Herpesvirus seropositivity in childhood associates with decreased monocyte-induced NK cell IFN-gamma production. J Immunol. 2009;182:25117. Medline:19201907 doi:10.4049/jimmunol.0801699

67 Pourahamad M, Hooshmand F, Olyaee Nezhad S, Sepidkar A. EBV seroepidemiology in married and unmarried women and men in Iran. Rep Biochem Mol Biol. 2014;2:94-7. Medline:26989728

68 He CS, Handzlik M, Muhamad A, Gleeson M. Influence of CMV/EBV serostatus on respiratory infection incidence during 4 months of winter training in a student cohort of endurance athletes. Eur J Appl Physiol. 2013;113:2613-9. Medline:23922172 doi:10.1007/s00421-013-2704-x

69 Khandaker GM, Stochl J, Zammit S, Lewis G, Jones PB. Childhood Epstein-Barr Virus infection and subsequent risk of psychotic experiences in adolescence: a population-based prospective serological study. Schizophr Res. 2014;158:1924. Medline:25048425 doi:10.1016/j.schres.2014.05.019

70 Rahimzadeh N, Otukesh H, Hoseini R, Riahifard A. Pretransplant Epstein-Barr virus serostatus and incidence of posttransplant lymphoproliferative disorder in pediatric renal transplants. Exp Clin Transplant. 2013;11:299-302. Medline:23905908 doi:10.6002/ect.2012.0204

71 Jansen MAE, van den Heuvel D, Bouthoorn SH, Jaddoe VWV, Hooijkaas H, Raat H, et al. Determinants of Ethnic Differences in Cytomegalovirus, Epstein-Barr Virus, and Herpes Simplex Virus Type 1 Seroprevalence in Childhood. J Pediatr. 2016;170:126-34.e1. Medline:26707579 doi:10.1016/j.jpeds.2015.11.014

$72 \mathrm{Yu}$ X, Ji MF, Yu YL, Cheng WM, Wu BH, Cao SM. Analysis of EB Virus antibodies levels and probability of suffering from nasopharyngeal carinoma in first-degree relatives of nasopharyngeal carinoma patients. China J Cancer Prev Treat. 2011;18:1825-7.

73 Durovic B, Gasser O, Gubser P, Sigle J, Hirsch HH, Stern M, et al. Epstein-Barr virus negativity among individuals older than 60 years is associated with HLA-C and HLA-Bw4 variants and tonsillectomy. J Virol. 2013;87:6526-9. Medline:23536655 doi:10.1128/JVI.00169-13

74 Michos A, Terzidis A, Kanariou M, Kalampoki V, Koilia C, Giannaki M, et al. Association of allergic sensitization with infectious diseases burden in Roma and non-Roma children. Pediatr Allergy Immunol. 2011;22:243-8. Medline:20573034 doi:10.1111/j.1399-3038.2010.01086.x

75 Wang GC, Han C, Detrick B, Casolaro V, Levine DM, Fried LP, et al. Herpesvirus Infections and Risk of Frailty and Mortality in Older Women: Women's Health and Aging Studies. J Am Geriatr Soc. 2016;64:998-1005. Medline:27131018 doi:10.1111/jgs.14090

76 Ford JL, Stowe RP. Racial-ethnic differences in Epstein-Barr virus antibody titers among U.S. children and adolescents. Ann Epidemiol. 2013;23:275-80. Medline:23621993 doi:10.1016/j.annepidem.2013.02.008

77 Birmann BM, Breen EC, Stuver S, Cranston B, Martinez-Maza O, Falk KI, et al. Population differences in immune marker profiles associated with human T-lymphotropic virus type I infection in Japan and Jamaica. Int J Cancer. 2009;124:61421. Medline:18989900 doi:10.1002/ijc.24012

78 Shapira Y, Poratkatz B-S, Gilburd B, Barzilai O, Ram M, Blank M, et al. Geographical differences in autoantibodies and anti-infectious agents antibodies among healthy adults. Clin Rev Allergy Immunol. 2012;42:154-63. Medline:21229335 doi:10.1007/s12016-010-8241-z

79 Dowd JB, Palermo T, Brite J, McDade TW, Aiello A. Seroprevalence of Epstein-Barr virus infection in U.S. children ages 6-19, 2003-2010. PLoS One. 2013;8:e64921. Medline:23717674 doi:10.1371/journal.pone.0064921

80 Spielmann G, Johnston CA, O'Connor DP, Foreyt JP, Simpson RJ. Excess body mass is associated with T cell differentiation indicative of immune ageing in children. Clin Exp Immunol. 2014;176:246-54. Medline:24401077 doi:10.1111/ cei. 12267

81 Thjodleifsson B, Olafsson I, Gislason D, Gislason T, Jogi R, Janson C. Infections and obesity: A multinational epidemiological study. Scand J Infect Dis. 2008;40:381-6. Medline:17943636 doi:10.1080/00365540701708293

82 Naenifard H, Arif AA, Huber LR, Warner J. Risk Factors of Epstein-Barr Virus Infection Among United States Children: Data From the National Health and Nutrition Examination Survey (NHANES), 2009-2010. J Prim Care Community Health. 2015;6:177-81. Medline:25711918 doi:10.1177/2150131915573472

83 Delaney AS, Thomas W, Balfour HH. Coprevalence of Epstein-Barr virus, cytomegalovirus, and herpes simplex virus type- 1 antibodies among United States children and factors associated with their acquisition. J Pediatric Infect Dis Soc. 2015;4:323-9. Medline:26582871 doi:10.1093/jpids/piu076

84 Bigley AB, Lowder TW, Spielmann G, Rector JL, Pircher H, Woods JA, et al. NK-cells have an impaired response to acute exercise and a lower expression of the inhibitory receptors KLRG1 and CD158a in humans with latent cytomegalovirus infection. Brain Behav Immun. 2012;26:177-86. Medline:21933704 doi:10.1016/j.bbi.2011.09.004

85 Saghafian-Hedengren S, Sohlberg E, Theorell J, Carvalho-Queiroz C, Nagy N, Persson JO, et al. Epstein-Barr virus coinfection in children boosts cytomegalovirus-induced differentiation of natural killer cells. J Virol. 2013;87:13446-55. Medline:24089567 doi:10.1128/JVI.02382-13

86 Saghafian-Hedengren S, Sverremark-Ekstrom E, Linde A, Lilja G, Nilsson C. Early-life EBV infection protects against persistent IgE sensitization. J Allergy Clin Immunol. 2010;125:433-8. Medline:19963258 doi:10.1016/j.jaci.2009.09.033 
87 van den Heuvel D, Jansen MAE, Dik WA, Bouallouch-Charif H, Zhao D, van Kester KAM, et al. Cytomegalovirus- and Epstein-Barr Virus-Induced T-Cell Expansions in Young Children Do Not Impair Naive T-cell Populations or Vaccination Responses: The Generation R Study. J Infect Dis. 2016;213:233-42. Medline:26142434 doi:10.1093/infdis/jiv369

88 Stowe RP, Ruiz RJ, Fagundes CP, Stowe RH, Chen M, Glaser R. An ELISA method to compute endpoint titers to Epstein-Barr virus and cytomegalovirus: application to population-based studies. J Immunol Methods. 2014;408:64-9. Medline:24859346 doi:10.1016/j.jim.2014.05.006

89 Pordeus V, Barzilai O, Sherer Y, Luiz RR, Blank M, Bizzaro N, et al. A latitudinal gradient study of common anti-infectious agent antibody prevalence in Italy and Colombia. Isr Med Assoc J. 2008;10:65-8. Medline:18300578

90 Burbelo PD, Ching KH, Morse CG, Alevizos I, Bayat A, Cohen JI, et al. Altered Antibody Profiles against Common Infectious Agents in Chronic Disease. PLoS One. 2013;8:e81635. Medline:24312567 doi:10.1371/journal.pone.0081635

91 Tesse R, Santoro N, Giordano P, Cardinale F, De Mattia D, Armenio L. Association between DEFB1 gene haplotype and herpes viruses seroprevalence in children with acute lymphoblastic leukemia. Pediatr Hematol Oncol. 2009;26:573-82. Medline:19954367 doi:10.3109/08880010903271705

92 Sokal EM, Hoppenbrouwers K, Vandermeulen C, Moutschen M, Leonard P, Moreels A, et al. Recombinant gp350 vaccine for infectious mononucleosis: a phase 2, randomized, double-blind, placebo-controlled trial to evaluate the safety, immunogenicity, and efficacy of an Epstein-Barr virus vaccine in healthy young adults. J Infect Dis. 2007;196:1749-53. Medline:18190254 doi:10.1086/523813

93 Hjalgrim H, Askling J, Sorensen P, Madsen M, Rosdahl N, Storm HH, et al. Risk of Hodgkin's disease and other cancers after infectious mononucleosis. J Natl Cancer Inst. 2000;92:1522-8. Medline:10995808 doi:10.1093/jnci/92.18.1522

94 Handel AE, Williamson AJ, Disanto G, Handunnetthi L, Giovannoni G, Ramagopalan SV. An updated meta-analysis of risk of multiple sclerosis following infectious mononucleosis. PLoS One. 2010;5:e12496. Medline:20824132 doi:10.1371/ journal.pone.0012496

95 Ascherio A, Munger KL. EBV and Autoimmunity. Curr Top Microbiol Immunol. 2015;390:365-85. Medline:26424654

96 Bonanni P, Breuer J, Gershon A, Gershon M, Hryniewicz W, Papaevangelou V, et al. Varicella vaccination in Europe - taking the practical approach. BMC Med. 2009;7:26. Medline:19476611 doi:10.1186/1741-7015-7-26

97 Azad MB, Lissitsyn Y, Miller GE, Becker AB. HayGlass KT, Kozyrskyj AL. Influence of socioeconomic status trajectories on innate immune responsiveness in children. PLoS One. 2012;7:e38669. Medline:22685596 doi:10.1371/journal. pone.0038669

98 Coimbra BM, Carvalho CM, Moretti PN, Mello MF, Belangero SI. Stress-related telomere length in children: A systematic review. J Psychiatr Res. 2017;92:47-54. Medline:28407508 doi:10.1016/j.jpsychires.2017.03.023

99 Disanto G, Pakpoor J, Morahan JM, Hall C, Meier UC, Giovannoni G, et al. Epstein-Barr virus, latitude and multiple sclerosis. Mult Scler. 2013;19:362-5. Medline:22767435 doi:10.1177/1352458512451942

$100 \mathrm{Li}$ Q, Bu W, Gabriel E, Aguilar F, Hoshino Y, Miyadera H, et al. HLA-DQ betal alleles associated with Epstein-Barr virus (EBV) infectivity and EBV gp42 binding to cells. JCI Insight. 2017;2:e85687. Medline:28239644 doi:10.1172/jci. insight.85687

101 Jabs WJ, Paulsen M, Wagner HJ, Kirchner H, Kluter H. Analysis of Epstein-Barr virus (EBV) receptor CD21 on peripheral B lymphocytes of long-term EBV- adults. Clin Exp Immunol. 1999;116:468-73. Medline:10361236 doi:10.1046/ j.1365-2249.1999.00912.x

102 Höcker B, Fickenscher H, Delecluse HJ, Bohm S, Kusters U, Schnitzler P, et al. Epidemiology and morbidity of Epstein-Barr virus infection in pediatric renal transplant recipients: a multicenter, prospective study. Clin Infect Dis. 2013;56:84-92. Medline:23042966 doi:10.1093/cid/cis823 